\title{
Extreme Velocity Fluctuations below Free Hydraulic Jumps
}

\author{
Raúl Antonio Lopardo \\ Instituto Nacional del Agua, AU Ezeiza-Cañuelas Km 1.65, 1804 Ezeiza, Argentina \\ Correspondence should be addressed to Raúl Antonio Lopardo; rlopardo@ina.gob.ar
}

Received 5 December 2012; Accepted 20 May 2013

Academic Editor: Michael Fairweather

Copyright (C) 2013 Raúl Antonio Lopardo. This is an open access article distributed under the Creative Commons Attribution License, which permits unrestricted use, distribution, and reproduction in any medium, provided the original work is properly cited.

\begin{abstract}
The internal flow of hydraulic jump is essentially an unsteady flow subjected to macroturbulent random fluctuations, and it was not known enough. Then, for the fluctuating motion interpretation, the experimental research on the associated turbulence must be necessary. The author developed in the past extensive laboratory research for the instantaneous pressure field determination by means of pressure transducers and new introductory experiments on velocity fluctuations by means of the ADV technique. The experimental study of the instantaneous pressure field was based on the knowledge of several statistical parameters of amplitudes and frequencies as functions of the Froude number, but for this paper the maximum instantaneous negative of pressure amplitudes on the floor is considered, in order to estimate the extreme maximum positive velocities near the bottom. A useful relationship between turbulence intensity and the pressure fluctuation coefficient $C_{p}^{\prime}$ was proposed from ADV velocity fluctuation for low incident Froude numbers. By means of this relationship, the value $u_{0,1 \%}^{\prime}$ (instantaneous positive semiamplitude with $0.1 \%$ of probability to be surpassed) can be considered for the determination of the turbulent extreme velocity near the bottom, under a free hydraulic jump stilling basin with incident Froude number $3<F_{1}<6$.
\end{abstract}

\section{Introduction}

Many researchers have studied hydraulic jump, but most of the works have focused on an integral analysis, and little is known about internal flow and turbulence characteristics. For physical knowledge of the hydraulic jump on a horizontal stilling basin, both the mean flow and the fluctuating motion are needed. The mean flow analysis allows the determination of the general pattern of the flow, such as water levels, the jump length, the macroscopic quantification of energy loss, and the mean pressure field.

The internal flow of hydraulic jump is essentially an unsteady flow subjected to macroturbulent random fluctuations, and it was not totally known enough. The author developed an extensive laboratory research for the instantaneous pressure field determination by means of pressure transducers and introductory experiments on velocity fluctuations by means of the ADV technique.

Early research on the turbulence characteristics of the hydraulic jump was carried out by Rouse et al. [1] using hot-wires techniques in an air model. Acoustic instruments methods were used in hydraulic jumps of low Froude number by Liu et al. [2]. They used a microacoustic Doppler velocity meter (ADV) and presented data of mean velocity, turbulence intensities, and Reynolds shear stresses, along with energy dissipation rate and Kolmogorov length scale calculations.

Previous studies showed that ADVs are capable of reporting accurate mean values of water velocity in three directions [3], even in low flow velocities. In addition, ADVs have proved to yield a good description of turbulence when certain conditions are satisfied [4]. These restrictions are related to the instrument configuration (sampling frequency and noise energy level) and flow conditions (convective velocity and turbulence scales in the flow).

On the other hand, former experimental studies on pressure fluctuations induced by hydraulic jump were published in English fifty years ago [5] and later by other authors [6,7].

Experimental research about pressure fluctuations below hydraulic jumps is not concluded, but the field of instantaneous pressure can be measured without technological problems. For the measurement of instantaneous velocities, the excess of turbulence in the hydraulic jump and the air bubbles incorporation induced certain questions about the accuracy of the instantaneous data obtained with ADV. For 
this reason, it was demonstrated [8], the possibility to use pressure fluctuations values to estimate turbulence intensities in the zone near the bed of a stilling basin.

Even if there is available bibliography about the turbulence decay along the hydraulic jump length, the experimental parameters were obtained by means of the standard deviation of the velocity near the bottom, and certainly the turbulence intensity is well represented, but it is not possible to know the real extreme instantaneous maximum velocity near the bottom.

This paper deals with experimental data of positive peak amplitudes of the longitudinal velocity component in macroturbulent flow induced by free hydraulic jumps downstream sluice gates. Amplitudes with $0.1 \%$ to occurrence probability of be surpassed with more positive amplitudes were used as a manner of giving a statistic value to those peaks.

\section{Experimental Setup and Experimental Method}

Free hydraulic jumps were generated downstream a sluice gate in a rectangular horizontal flume with both acrylic bottom and sidewalls, $0.65 \mathrm{~m}$ wide, $1.00 \mathrm{~m}$ deep, and $12.00 \mathrm{~m}$ long. The tailwater depth was controlled by a vertical tailgate located at the end of the flume. Two experiments were performed, and Figure 1 includes the main details of these experiments. All experiments were conducted with a gate opening equal to $0.07 \mathrm{~m}$. A usual gage was used to measure the subcritical water depth $z_{2}$ located $6 \mathrm{~m}$ downstream from the sluice gate.

The mean velocity $U_{1}$ at location $z_{1}$ was varied in order to obtain two different incident Froude numbers, $F_{1}=3.03$ and $F_{1}=4.88$. The incident Reynolds number, $\operatorname{Re}_{1}=U_{1} \cdot z_{1} / v$ (where $v$ is the cinematic viscosity), was in the order of $\operatorname{Re}_{1}=$ $10^{5}$.

The random pressure components were measured with bidirectional pressure transducers with fully active straingage bridge. Data were processed and analyzed in terms of discrete sample values. The sampling interval in time adopted was 0.01 seconds, according to the sampling theorem for random records. The number of samples taken at every point was 16,384 (32 blocks of 512 values each one). The experimental methodology for measurement and data analysis of pressure fluctuations below free hydraulic jumps was based on a previous research [9].

\section{Pressure Fluctuations and Turbulence Intensity}

The intensity of isotropic turbulence in open channel flows is usually expressed by the relationship between the root mean square of the velocity fluctuation and the mean velocity in the point considered

$$
I=\frac{\sqrt{\overline{u^{\prime 2}}}}{U} .
$$

On the other hand, for structural purposes, the turbulence intensity can also be defined as a function of pressure

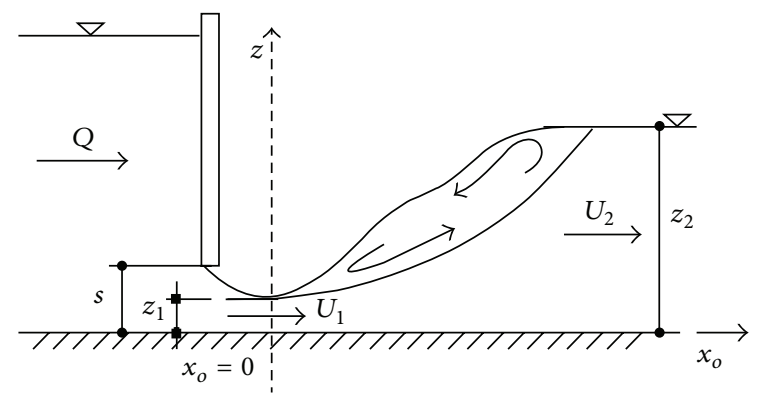

Figure 1: Definition sketch of free hydraulic jump.

fluctuations on a flow boundary, usually [7] by means of the nondimensional parameter $C_{p}^{\prime}$

$$
C_{p}^{\prime}=\frac{\sqrt{\overline{p^{\prime 2}}}}{\rho\left(U_{1}^{2} / 2\right)} .
$$

By means of the dimensional analysis, for a free steady hydraulic jump, it is possible to obtain the following parameters, for turbulence intensity at the level $z=1 \mathrm{~cm}$ (due to ADV accuracy restriction) and pressure fluctuations on the bed $(z=0)$, respectively:

$$
\begin{aligned}
& \frac{\sqrt{\overline{u^{\prime 2}}}}{U_{1}}=\Phi_{1}\left[\frac{x}{\left(z_{2}-z_{1}\right)}, F_{1}\right], \\
& C_{p}^{\prime}=\Phi_{2}\left[\frac{x}{\left(z_{2}-z_{1}\right)}, F_{1}\right] .
\end{aligned}
$$

The pressure fluctuation amplitude in a turbulent flow can to be obtained from the instantaneous velocity field, by the separation of the mean and fluctuating variables in the known Poisson equation [10]. If the turbulence can be considered as homogeneous and isotropic, it can be expressed:

$$
\sqrt{\overline{p^{\prime 2}}}=\alpha \rho \overline{u^{\prime 2}}
$$

where $\rho$ is the fluid density and $\alpha$ is a nondimensional coefficient [11].

Taking into account that the mean velocity $U$ in each point of measurement is connected with the mean velocities in the jump incident section $U_{1}$ and in the downstream section $U_{2}$, it is possible to propose the following functions for calculations:

$$
\begin{gathered}
\frac{\overline{u^{\prime 2}}}{U_{1}}=\lambda \sqrt{C_{p}^{\prime}}, \\
\frac{\overline{u^{\prime 2}}}{U_{2}}=\left(\frac{\lambda}{2}\right)\left(\sqrt{1+8 F_{1}^{2}}-1\right) \sqrt{C_{p}^{\prime} .}
\end{gathered}
$$

In order to have a good agreement between turbulence intensity direct measurements with calculated values from pressure fluctuations determinations for two different incident Froude numbers $\left(F_{1}=3\right.$ y $\left.F_{1}=5\right)$, the nondimensional coefficient proposed is $\lambda=0.6[8]$. 


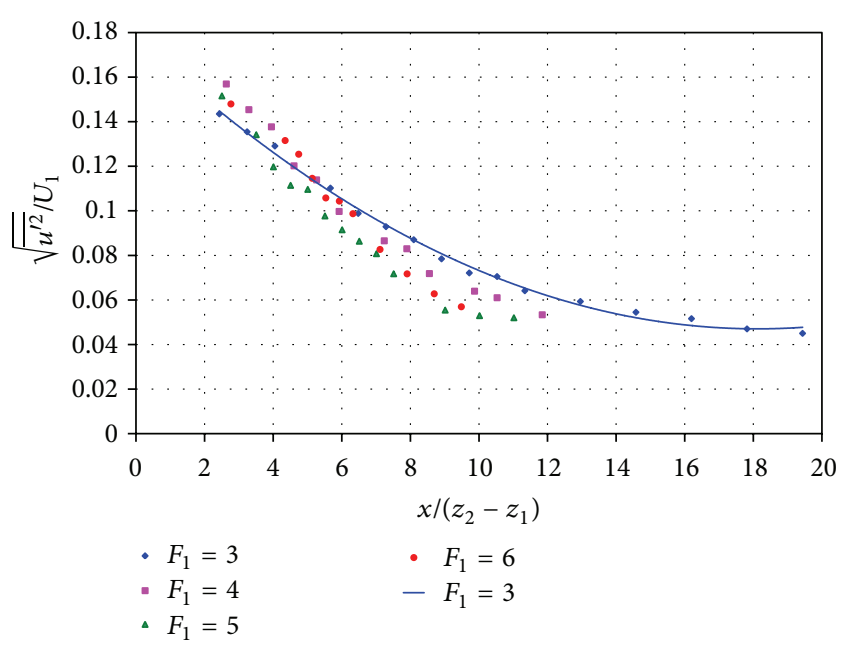

FIgURE 2: Turbulence intensity along free hydraulic jump.

\section{Experimental Results}

The turbulence intensity determination, as defined in (6) (by direct velocity measurements or through indirect measurements by pressure fluctuations), represents the ratio between mean square values of velocity fluctuation and the incident mean velocity of the hydraulic jump. Figure 2, where the vertical axis is $\sqrt{\overline{u^{\prime 2}}} / U_{1}$ and the abscissa is $x /\left(z_{2}-z_{1}\right)$, presented in a previous publication [8], allows appreciation some results referring to (3) for free hydraulic jumps. The experimental data was exposed as a function of the incident Froude number $F_{1}$. The curve was plotted for the lower incident Froude number tested, $F_{1}=3$. The length usually used to define the length of stilling basin protection horizontal is $x /\left(z_{2}-z_{1}\right)=6$, but it is observed that in this point the rms value of velocity fluctuation reaches about $10 \%$ of the mean incident velocity $U_{1}$.

As noted in the case of pressure fluctuations below hydraulic jump stilling basins, the maximum positive pressure fluctuating amplitude on the floor of a hydraulic jump is much greater than the mean square value, which is usually considered for conventional analysis of turbulence decay. For practically all authors, it is a suitable parameter for this purpose.

However, when it is desired to know the maximum value of instantaneous velocities on the bed, for example, to design rock protections downstream stilling basins, it is more relevant to take into consideration the maximum positive amplitude of velocity fluctuation as the value with $0.1 \%$ of probability to be overtaken by another registered value $\left(u_{\max }^{\prime}\right)$, assuming that this is the order of magnitude for the maximum detectable instantaneous velocity on experimental measurements.

Figures 3 and 4 show the variation of the parameter $u_{\max }^{\prime} / U_{1}$ as a function of $x /\left(z_{2}-z_{1}\right)$ for the four incident Froude numbers considered. It can be seen that for any incident Froude number, extreme amplitudes $u_{\max }^{\prime} / U_{1}$ have a peak around the abscissa $x /\left(z_{2}-z_{1}\right)=3$ and the values

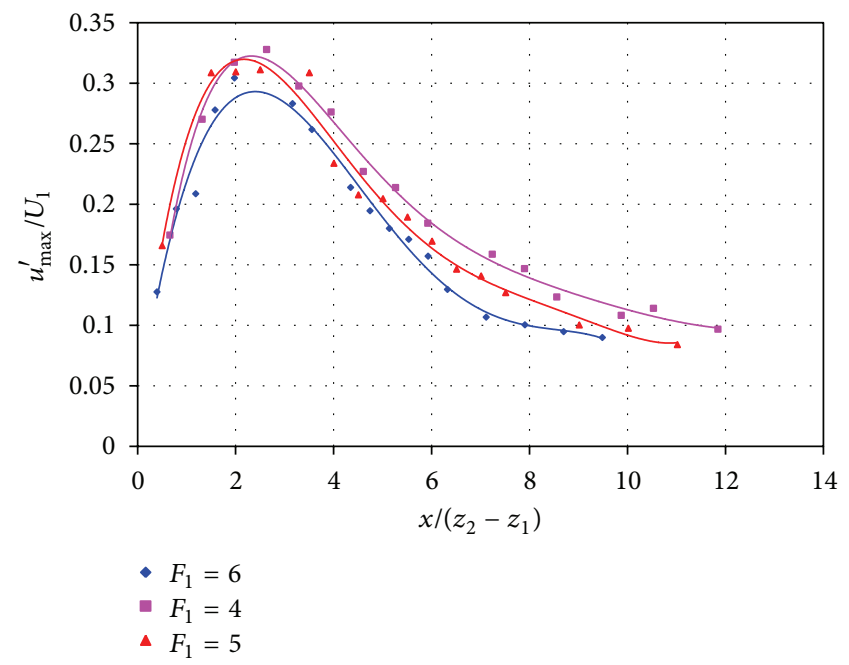

FIGURE 3: Maximum velocities below hydraulic jumps near the floor for $F_{1} \geq 4$.

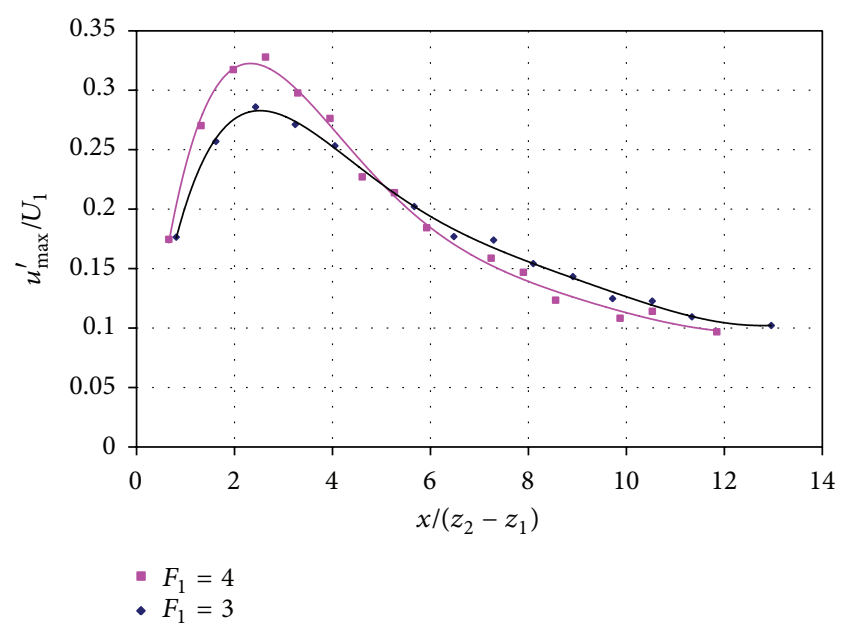

FIGURE 4: Maximum velocities below hydraulic jumps near the floor for $F_{1} \leq 4$.

grow with the incident Froude number. The above conclusion is clearly stated in Figure 5, which also shows that the peaks occur in the vicinity of $x /\left(z_{2}-z_{1}\right)=3$. For $x /\left(z_{2}-z_{1}\right) \leq$ 4 , the maximum amplitudes occur for $F_{1} \approx 4$, while for $x /\left(z_{2}-z_{1}\right)>4$ amplitudes decrease with the value of $F_{1}$. This assumption is clearly stated in Figure 4, which shows that the conclusion is only true for $F_{1}=3$ in the upstream region, because from $x /\left(z_{2}-z_{1}\right) \approx 5$ the maximum amplitudes data exceed the values for $F_{1}=4$. This abscissa, where a change of curvature of the lines plotted can be seen, is closed with the value $x /\left(z_{2}-z_{1}\right) \approx 4.97$, which was demonstrated as the point for the boundary layer separation on the floor below a hydraulic jump [12].

Briefly, it is interesting that the maximum positive velocity amplitudes measured for the range $3<F_{1}<6$ are in the order of $25 \%$ of the incident velocity.

Taking into account that always the maximum velocities needed to scour process calculations are those near the bottom, they are considered in the present analysis, located 


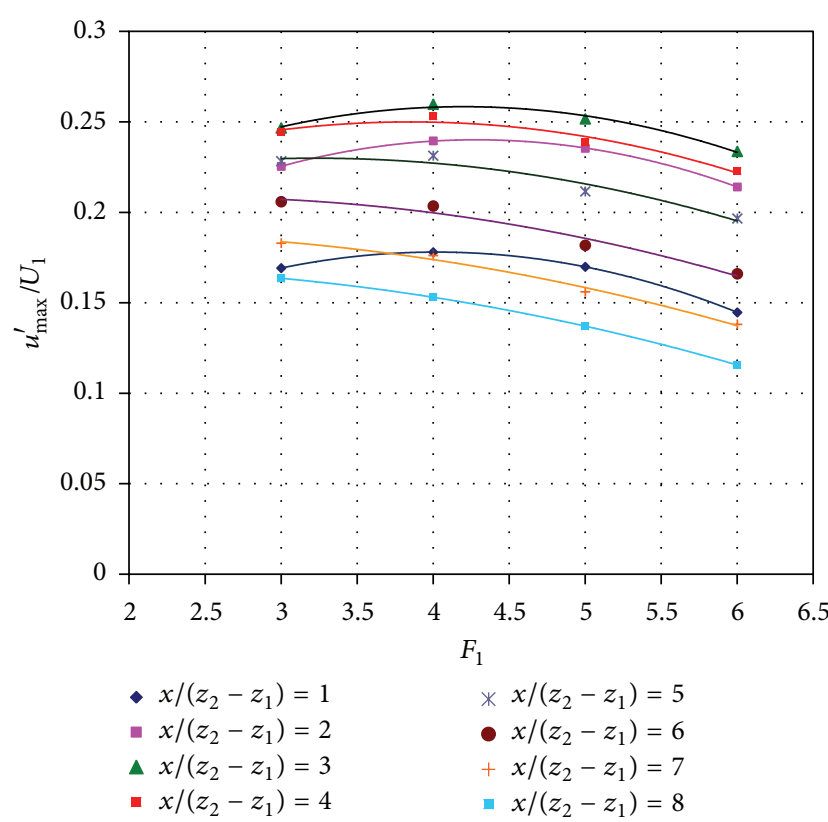

FIGURE 5: Maximum velocities below hydraulic jumps near the floor as a function of $F_{1}$.

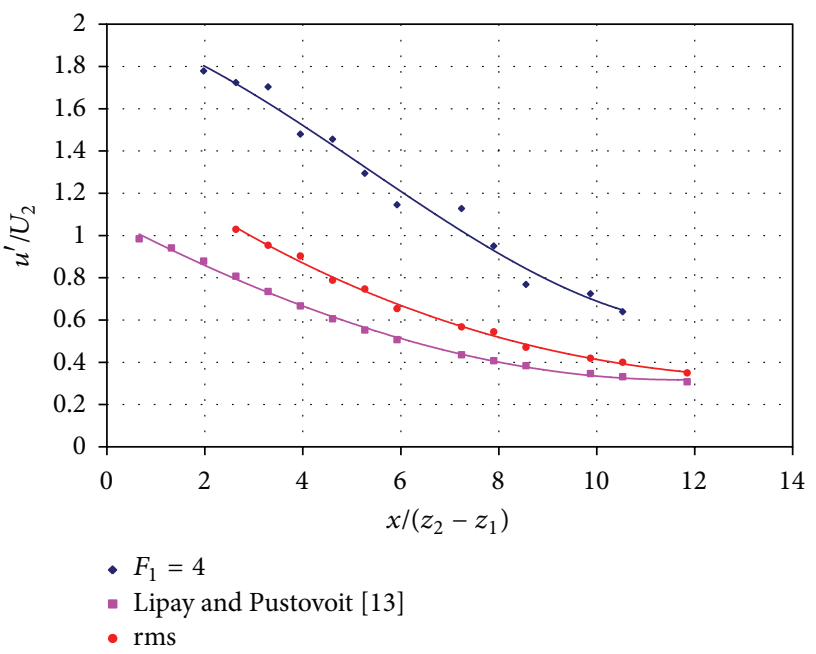

FIGURE 6: Extreme velocity near the bottom in free hydraulic jump for $F_{1}=4$.

in the downstream zone of the hydraulic jump, where erosion problems would be present. Then, from the first historic bibliographic reference detected [13], the extreme velocity fluctuation near the bottom was related to the downstream jump velocity $U_{2}$, theoretically calculated by the application of the Bélanger equation.

Due to the previous considerations, Figure 6 shows the experimental results of $u_{\max }^{\prime} / U_{2}$ as a function of $x /\left(z_{2}-z_{1}\right)$ for the incident Froude number condition $F_{1}=4$. The figure allows to observe that the maximum instantaneous amplitude for the "classical length" of the hydraulic jump $x /\left(z_{2}-z_{1}\right)=6$ is 1.2 times the mean downstream velocity $U_{2}$, which explains the important local scour always detected downstream the stilling basins concrete protection.
Historical values obtained by Lipay and Pustovoit are clearly below those proposed in the present research and reasonably near to the author's values calculated from the root mean square amplitudes, perhaps because these are the values usually measured from instantaneous velocity measurements below hydraulic jumps. Recently, other authors [14] published ADV observations on the turbulence in the transition region from the end of jump to open channel flow for $F_{1}=4$ and $F_{1}=7$, showing Reynolds normal stresses and shear stress, also useful in assessing the bed erodibility downstream the hydraulic jump stilling basins.

\section{Conclusion}

Turbulence intensity is defined as the relationship between the rms velocity fluctuation $\overline{u^{\prime 2}}$ and the mean velocity of the considered point $U$. For design purposes, as the mean value is not known at any point of the hydraulic jump, the use of either the upstream velocity $U_{1}$ or the downstream velocity $U_{2}$ is needed. On the other hand, the maximum positive amplitude of velocity fluctuation can be defined as the positive amplitude with $0.1 \%$ of probability to be overtaken by another registered value $\left(u_{\max }^{\prime}\right)$. This value can be obtained just over the floor, from pressure fluctuation experimental tests, by means of a useful relationship between turbulence intensity and the pressure fluctuation coefficient $C_{p}^{\prime}$.

Following previous experimental conclusions, all the tests for velocities and pressure were accomplished for incident Reynolds number $R_{1}$ up to 100,000 and sluice gate openings larger than $3 \mathrm{~cm}$ and for incident Froude numbers between $F_{1}=3$ and $F_{1}=6$. The magnitude of instantaneous actions is analysed, in order, for example, to estimate the representative dimensions of rip-rap for fluvial beds protection downstream the hydraulic jump stilling basins.

\section{References}

[1] H. Rouse, T. T. Siao, and S. Nagaratnam, "Turbulence characteristics of the hydraulic jump," Journal of Transportation Engineering, vol. 124, pp. 926-950, 1959.

[2] M. Liu, N. Rajaratnam, and D. Z. Zhu, "Turbulence structure of hydraulic jumps of low Froude numbers," Journal of Hydraulic Engineering, vol. 130, no. 6, pp. 511-520, 2004.

[3] N. C. Kraus, A. Lohrmann, and R. Cabrera, "New acoustic meter for measuring 3D laboratory flows," Journal of Hydraulic Engineering, vol. 120, no. 3, pp. 406-412, 1994.

[4] C. M. García, M. Cantero, Y. Niño, and M. H. García, "Turbulence measurements with acoustic doppler velocimeters," Journal of Hydraulic Engineering, vol. 131, no. 12, pp. 1062-1073, 2005.

[5] N. A. Preobrazhenski, "Laboratory and field investigation of flow pressure pulsation and vibration of large dams," in Proceedings of the 7th Congreso Mundial de Grandes Presas (ICOLD '58), 1958.

[6] V. O. Vasiliev and B. V. Bukreyev, "Statistical characteristics of hydraulic jump," in Proceedings of the 12th IAHR Congress, vol. 2, pp. 1-8, Fort Collins, Colo, USA, 1967. 
[7] R. A. Lopardo, J. C. de Lio, and G. F. Vernet, "Physical modeling on cavitation tendency for macroturbulence of hydraulic jump," in Proceedings of the International Conference on the Hydraulic Modeling of Civil Engineering Structures, pp. 109-121, BHRA, Coventry, UK, 1982.

[8] R. A. Lopardo and M. Romagnoli, "Pressure and velocity fluctuations in stilling basins," in Advances in Water Resources \& Hydraulic Engineering, C. Zhang and H. Tang, Eds., vol. 6, pp. 978-973, Springer, 2009.

[9] R. A. Lopardo and R. E. Henning, "Experimental advances on pressure fluctuations beneath hydraulic jumps," in Proceedings of the 21st IAHR Congress, vol. 3, pp. 633-638, Melbourne, Australia, 1985.

[10] A. Favre, L. S. G. Kovasnay, R. Dumas, J. Gaviglio, and M. Coantic, La Turbulence en Mécanique des Fluides, GauthiersVillars, Paris, France, 1976.

[11] G. K. Batchelor, "Pressure fluctuations in isotropic turbulence," Mathematical Proceedings of the Cambridge Philosophical Society, vol. 47, no. 2, pp. 359-374, 1951.

[12] R. A. Lopardo and J. M. Casado, "Boundary layer separation beneath submerged jump flows," in Proceedings of the 32nd IAHR Congress, vol. 2, p. 584, Venecia, Italy, 2007.

[13] I. E. Lipay and V. G. Pustovoit, "On the vanishing of intensiv macroturbulence in open channel below hydraulic structure," in Proceedings of the 12th IAHR Congress, vol. 2, pp. 362-369, Fort Collins, Colo, USA, 1967.

[14] A. T. M. H. Zobeyer, N. Jahan, Z. Islam, G. Singh, and N. Rajaratnam, "Turbulence characteristics of the transition region from hydraulic jump to open channel flow," Journal of Hydraulic Research, vol. 48, no. 3, pp. 395-399, 2010. 

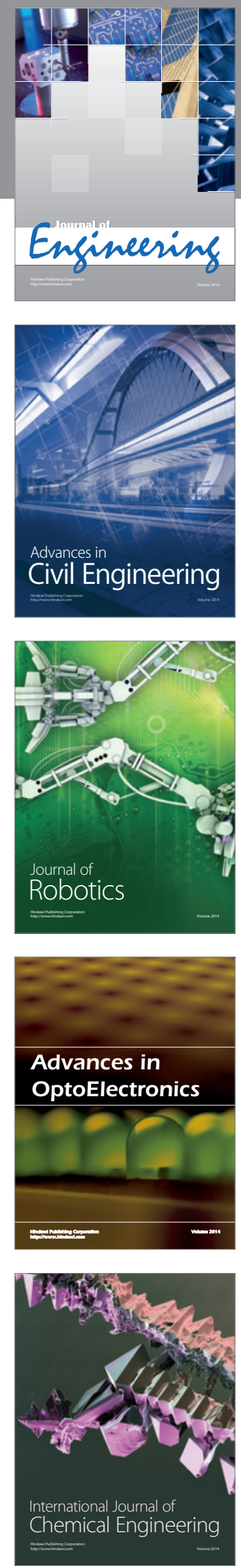

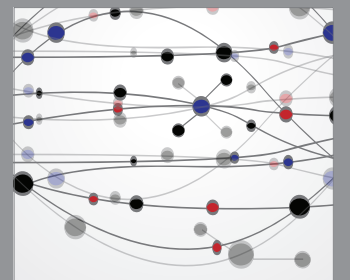

The Scientific World Journal
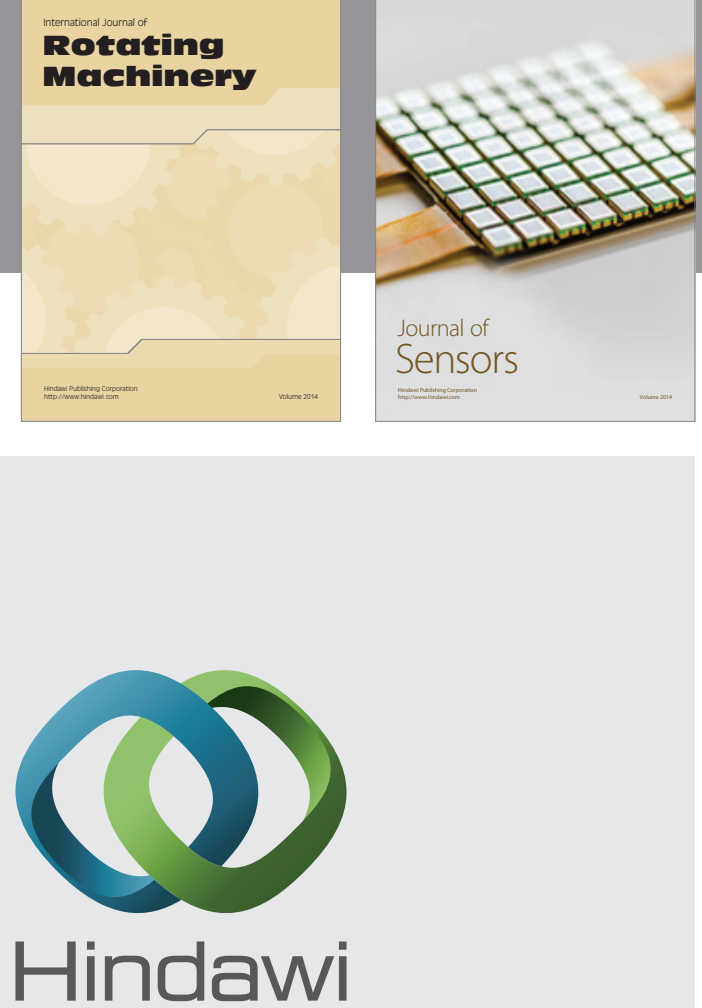

Submit your manuscripts at http://www.hindawi.com
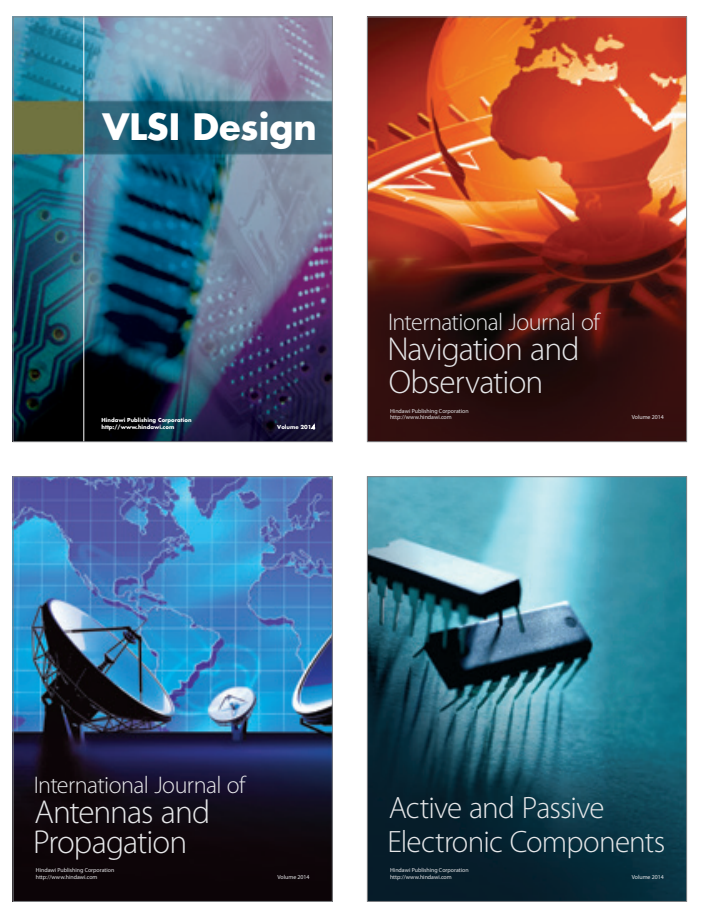
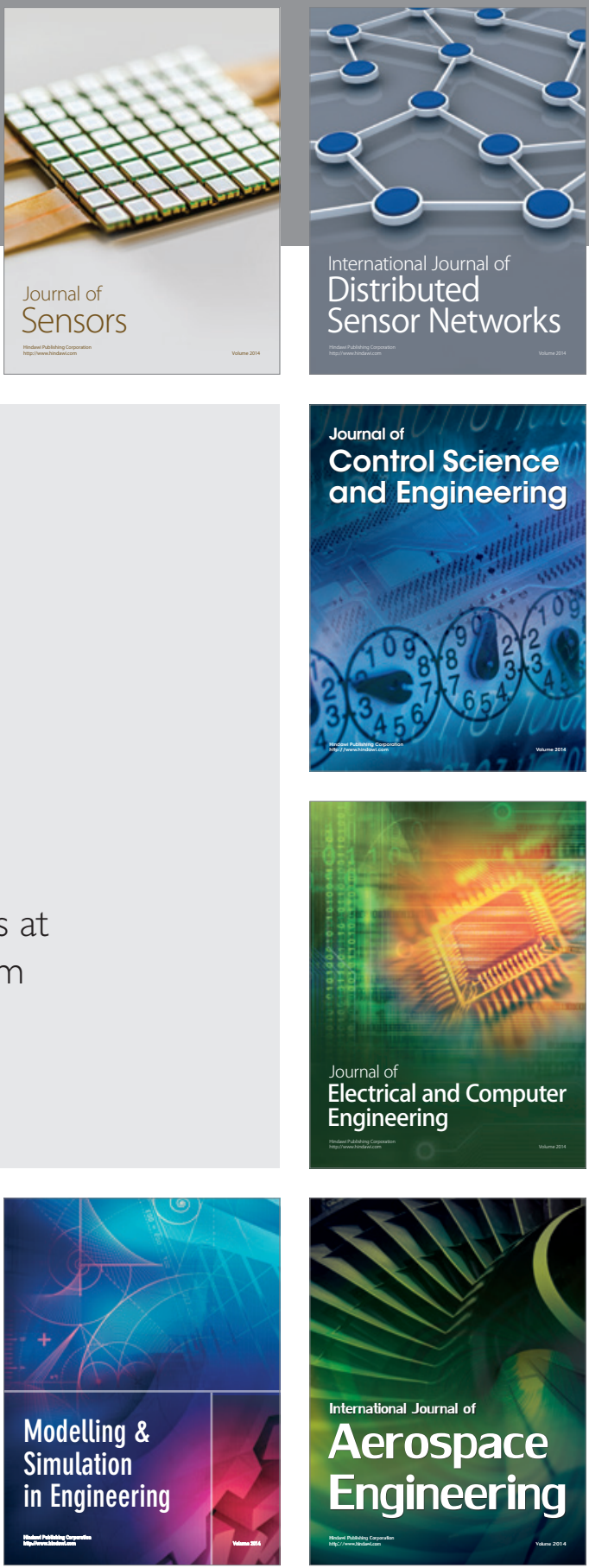

Journal of

Control Science

and Engineering
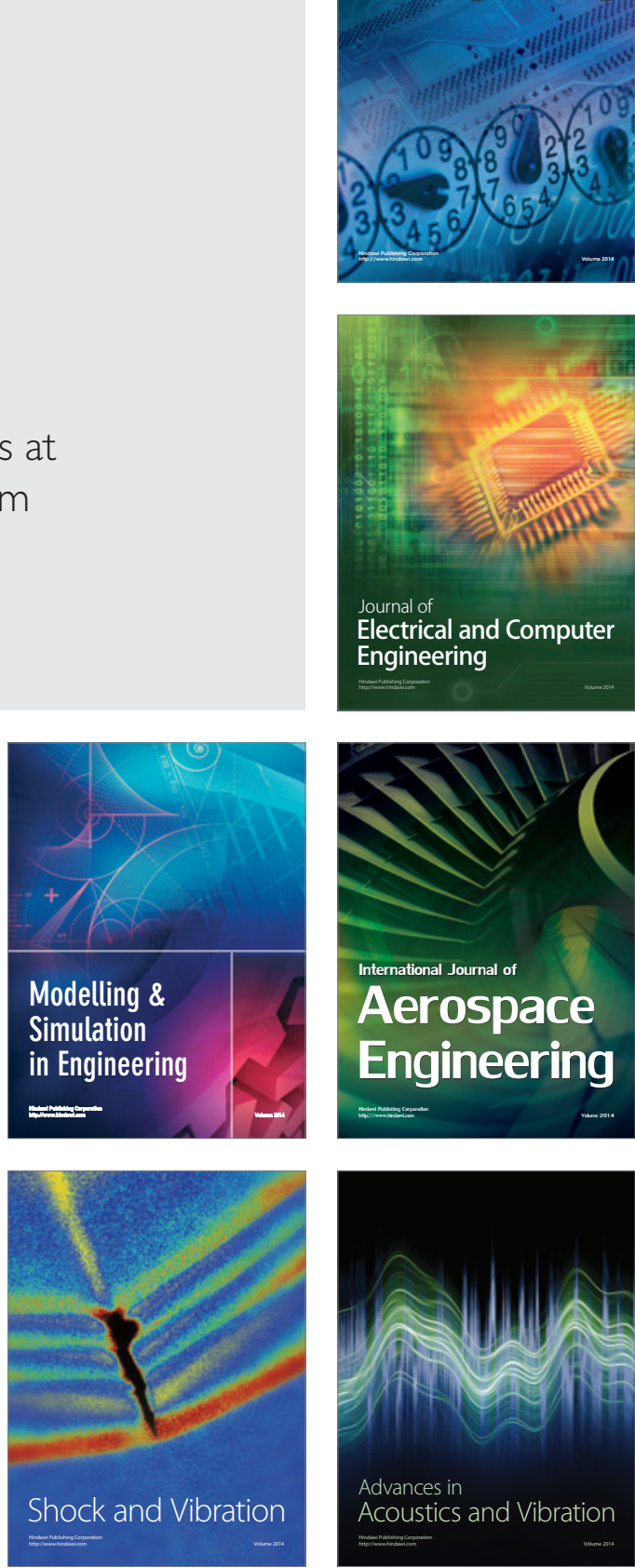